\title{
CONTINUOUS IMPROVEMENTS IN THIRD YEAR CHEMICAL ENGINEERING DESIGN
}

\author{
Graeme Norval ${ }^{1}$, Erin Bobicki ${ }^{2}$ \\ ${ }^{1}$ Department of Chemical Engineering and Applied Chemistry \\ ${ }^{2}$ Department of Material Science and Engineering \\ University of Toronto \\ graeme.norval@utoronto.ca \\ erin.bobicki@utoronto.ca
}

\begin{abstract}
An impending retirement has led us to reevaluate the course: should we keep it - and if so who teaches it, or should we look to change it? The course was co-taught with a new faculty member, coupled with internal reviews and discussions. Ultimately, we decided to keep the course, and also to work to broaden its base.

Historically, the design problems have been petrochemical in nature. Each team gets a reaction, with a first order rate law, as well as a production rate and fractional conversion. From this, they do the design calculations for a reactor and separator, and also generate the base engineering drawings.
\end{abstract}

This past year, the project types were expanded to include environmental remediation and hydrometallurgical extraction. The environmental remediation problems involved wastewater processing (eg., BOD oxidation) which can be treated as a first order reaction. The hydrometallurgical problem (Li leaching from spodumene) also was set up as first order. Additionally, we provided the option of a case study review. The students chose a classic chemical safety incident, reviewed the details, and created a summary report which included recommendations on how to incorporate learnings from the incident into the curriculum.

Keywords: design projects; case studies in design; safety in design; active learning

\section{INTRODUCTION}

The Canadian Engineering Accreditation Board has had the requirement for a "capstone design" experience for many years. "The engineering curriculum must culminate in a significant design experience conducted under the professional responsibility of faculty licensed to practise engineering in Canada. The significant design experience is based on the knowledge and skills acquired in earlier work and it preferably gives students an involvement in team work and project management [1]."

The Department of Chemical Engineering and Applied Chemistry has had a mandatory "Chemical Plant Design" capstone course since 1981. It is typical of such chemical engineering projects in that the problems are industrially relevant, open-ended, require that the students use a variety of engineering tools, and that they are supervised by licensed engineers [2]. These courses are useful in linking a variety of engineering aspects into one experience. Students respond positively to the projects, which is not surprising given that engineering students are Visual, Sensing, Inductive, and Active learners [3].

These capstone courses also have weaknesses. These include mismatches between the student's interests and skills and the project/task to which they are assigned, and, the student teams don't have an experienced senior engineer. It is quite common for the students to "spin their wheels" trying to resolve a question for which there is an easy answer. The move to introduce elements of Safety Management into the design curriculum adds a key design tool, that of determining the impact of input deviations on the product of process, as well as the knock-on effects on downstream process steps.

About 10 years ago, we introduced a design course into our $3 \mathrm{~S}$ (January to April) term at the University of Toronto. This course is presented, along with our key learnings. Our pilot improvements are presented, along with a discussion of the student results.

\section{THIRD YEAR DESIGN COURSE}

The third-year design course is a project only course. The projects reinforce and integrate the material taught in three core courses (Reactor Design, Separations, Process Dynamics and Control) in the same term. One of the course design goals was to keep the number of project deliverables low, to allow for deeper dive on the key learning outcomes. Perhaps it is better to say that the course and project design has the goal of removing barriers to success. 
Cornesky teaches that students will be unable to do quality work unless you:

- believe that they can do it,

- $\quad$ are available to coach and assist them, and

- provide feedback and the opportunity to improve [4].

These thoughts were key in the development of the course.

There is one stoichiometric reaction for each project; parallel and sequential reactions are excluded. A first order rate expression is provided, along with a production target and fractional conversion. The chemical species are well known and the thermodynamic and physical properties are readily obtained.

The project requirements generally include: sizing of an isothermal reactor, sizing of an adiabatic reactor, development of a McCabe-Thiele diagram and sizing of a distillation column, creation of a process flow diagram (PFD), creation of a simulation (ASPENPLUS) of the process with recycle of the unreacted raw material, and development of a piping and instrumentation diagram (P\&ID). There is one deliverable - a short report (20-page maximum), with the supporting calculation and drawing files.

The course is structured with 4 two-hour tutorial sections and a one-hour lecture per week. Each student attends one assigned tutorial time and this is where most of the teaching and learning occurs. Lectures cover content of interest to the whole class and are held primarily in the first half of the term, and then as needed.

The students create their own teams of 3 or 4 . The student teams meet with the course instructors, as well as a teaching assistant, during the tutorials. Usually, these meetings with the instructor and TAs are done separately. A key learning outcome is for the students to learn how to work in groups and manage their time. A component of this is for the students to understand their own personality and work style. Students take a Myers-Briggs personality test and discuss the results with their group. The groups use this information, as well as self-knowledge of work habits and communication styles, to plan how the group will function and complete the course requirements on time, considering course load and commitments outside of school. The students are tasked with preparing a goal and agenda for each meeting. The students come with the problems they are encountering, and our role is to help them resolve the problems. Most often, the students have one specific calculation issue - we help them resolve that, and agree on the next work steps. As instructors we take a "coach and assist" role, similar to that of a senior engineer.

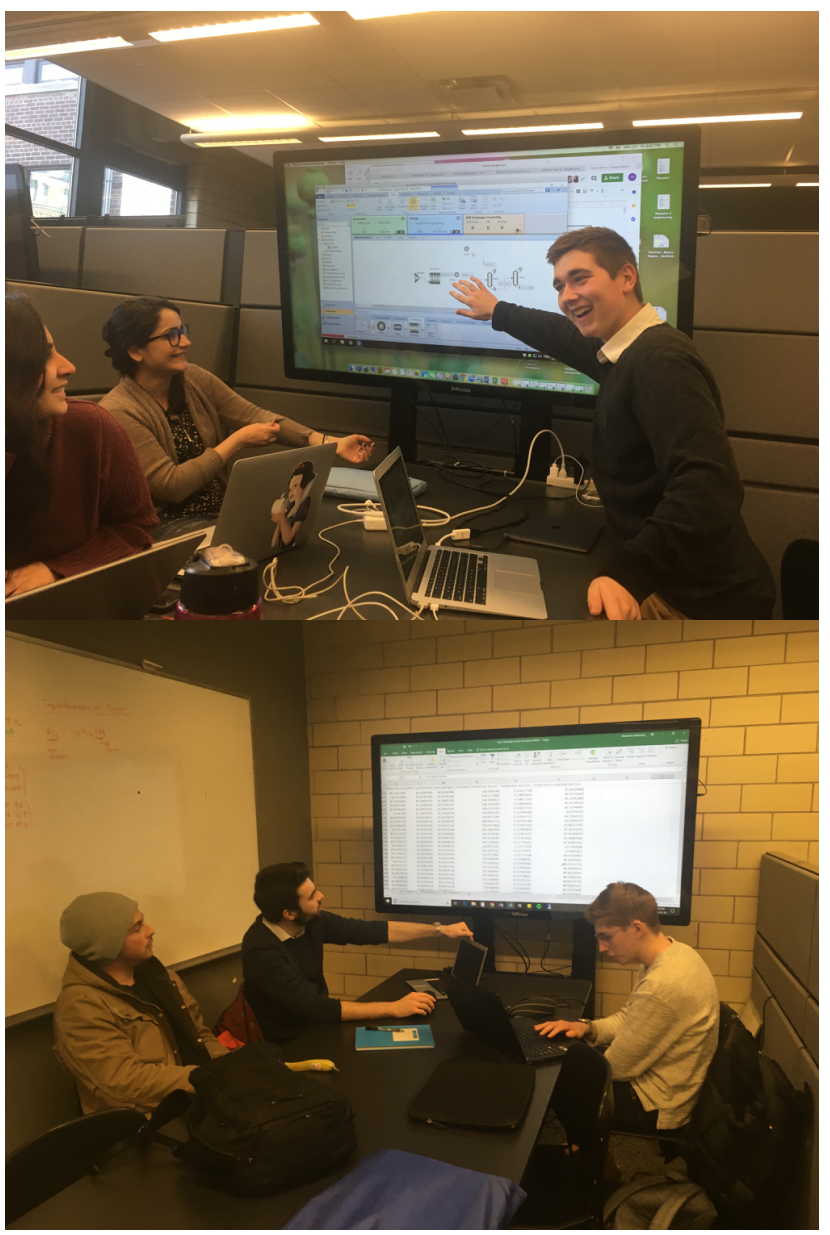

Fig. 1. Typical Tutorial Scenes

The students are introduced to the "10 Deviations", which are guidewords in a hazard study. The development of the P\&ID requires a team discussion of the deviations; this skill is introduced to each team individually when they are ready to begin that analysis.

Table 1: The 10 Deviations

\begin{tabular}{|l|l|}
\hline Deviation Guide Words & Comments \\
\cline { 1 - 2 } No, None, Not & $\begin{array}{l}\text { Used for flow, } \\
\text { temperature, pressure, } \\
\text { level, and concentration } \\
\text { variables }\end{array}$ \\
\cline { 1 - 2 } More, Higher, Greater \\
\cline { 1 - 1 } Reverse & $\begin{array}{l}\text { Used for a design intent or } \\
\text { action }\end{array}$ \\
\cline { 1 - 1 } Part of & $\begin{array}{l}\text { Used mostly in batch } \\
\text { In addition to } \\
\text { orocesses where time } \\
\text { Instead of }\end{array}$ \\
\cline { 1 - 2 } Sooner than &
\end{tabular}


The course has been quite successful. The failure rates in the three associated core courses has been reduced; for example, in the core reactor design course, the data is 9 failures and $3 \mathrm{~A}+$ in a class of 106 and average of 66.8 (2011), to 2 failures and $9 \mathrm{~A}+$ in a class of 112 (2018) . These courses have the same instructors and the same textbooks. The workload in the capstone course has remained the same, but the students manage their time much more effectively. There are virtually no team dynamics issues with our capstone course. The students understand the basics of process safety, and are known to contribute in that area during their final work terms.

\section{TIME FOR A CHANGE}

With the forthcoming retirement of the course instructor, Professor Norval, the program needed to make two decisions. The first was whether to keep a design course in the $3^{\text {rd }}$ year; and if the course remains, should it be modified to adapt to current trends. There was strong support to both retain and strengthen the course, and Professor Bobicki agreed to take it over. The phased retirement time has enabled for a smoother transition.

The first structural change was to create "on-line" assignments in the Learning Management System. The students determine their Myers-Briggs personality types (MBTI), and receive a grade for completing it in the first week. Students receive grades for watching videos related to the process safety management aspects. "One Night in Bhopal" demonstrates the importance of layers of protection [5]. "Fukushima Daiichi: The Path to Nuclear Meltdown" introduces the issues of risk communication and disaster preparedness [6]. Safety and professionalism is introduced through an e-learning module [7]. Other support materials, such as guidance on engineering drawing and process simulation, as well as report writing are posted as modules.

The second change was to broaden the nature of the projects. A set of environmental projects was created using the same key principles. Wastewater treatment involves reactions and separations as well as control and design for deviations in the feed variables (flowrate, temperature, etc.). Several teams chose to do this type of a project. One team chose to investigate a hydrometallurgical extraction process. Here, lithium is extracted (separated) from spodumene ore, and then precipitated to produce pure lithium carbonate, for subsequent processing for lithium batteries. These projects involve the basic features of reaction and separation, and require modelling of the system both algebraically and in ASPENPLUS.

The third change was to offer the possibility of analyzing a case study. Case study learning is commonly used in MBA courses. The incident reports from major chemical accidents were chosen as the basis for pool; the cases needed to be public, and to require the application of some engineering tools. The students would be able to go through a HAZID or Deviations type approach to consider the technical causes of the incidents. The short list of cases was: BP Macondo [8], Lac Megantic [9], MGPI Processing [10] or Fernie Memorial Arena [11].

The cases appear quite different, but they all touch on the same key elements. The offshore oil industry is moving to deeper waters, but the technologies and regulatory framework were proven through losses in shallow water; Figure 2 shows the progression to deeper water wells in the US Gulf. The MMA train was parked on the sloping main line, immediately adjacent to a siding which has a derail, as seen in Figure 3. There are 5 chemicals received by MGPI, and the connections are seen in Figure 4. The ammonia chiller was due for a replacement in 2010, but the replacement had been deferred multiple times; further an ammonia leak was identified during the spring shutdown (April 2017), but not repaired prior to the fall startup (Figure 5).

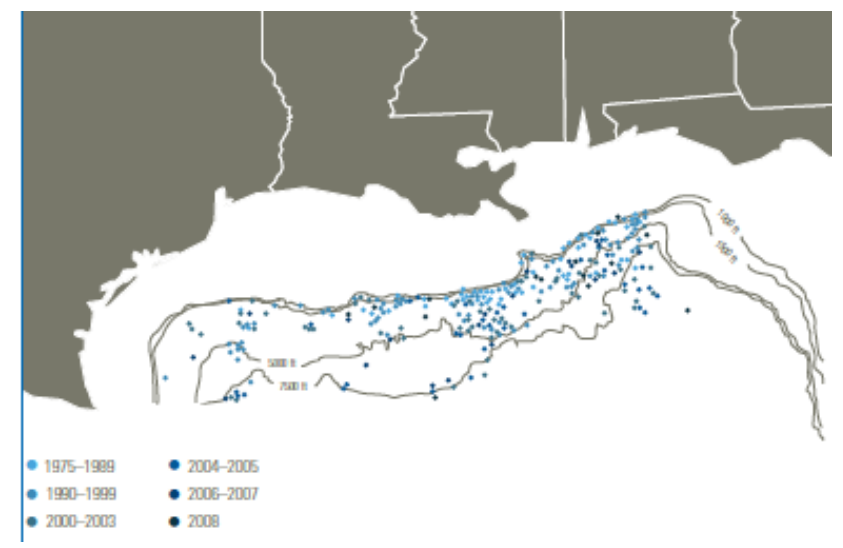

Fig. 2. Progression to Deeper Water Wells [8]

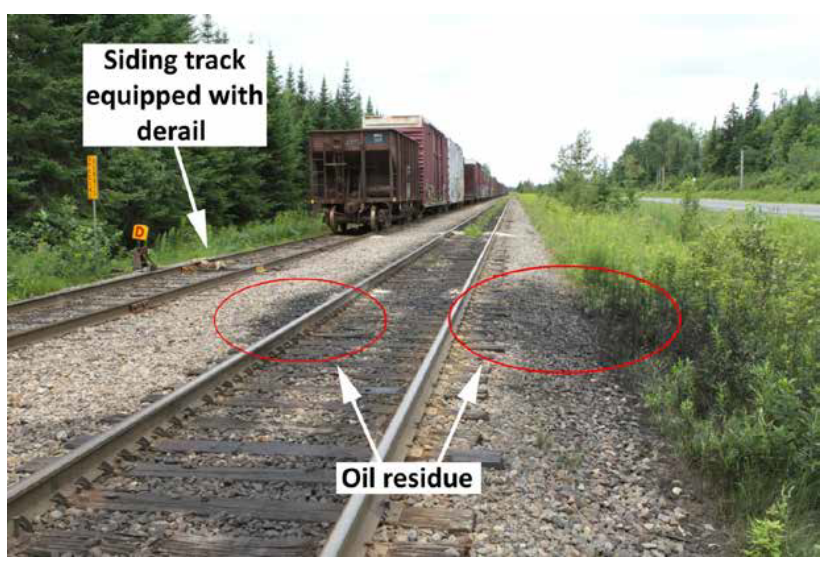

Fig. 3. Main Line and Siding at Nantes [9] 


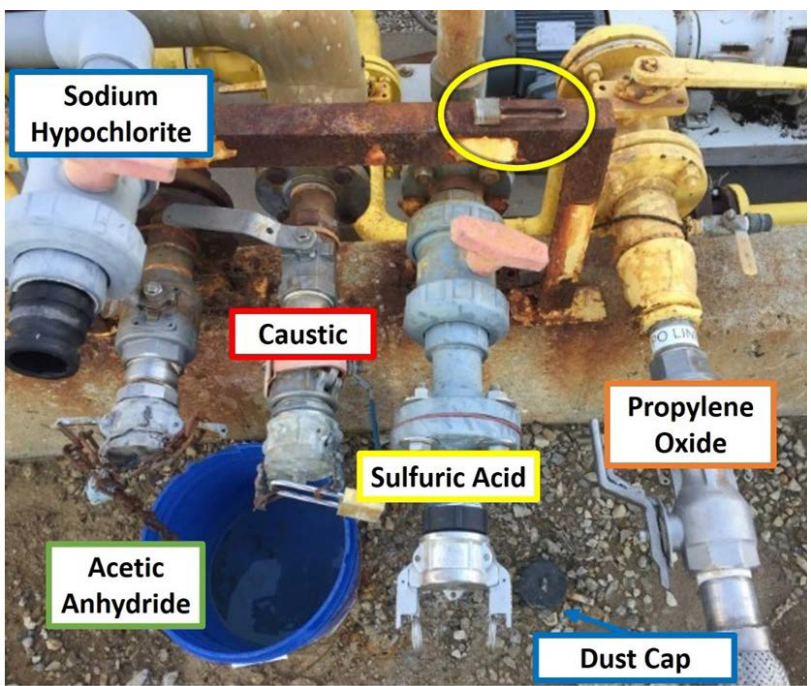

Fig. 4. MGPI Unloading Station [10]

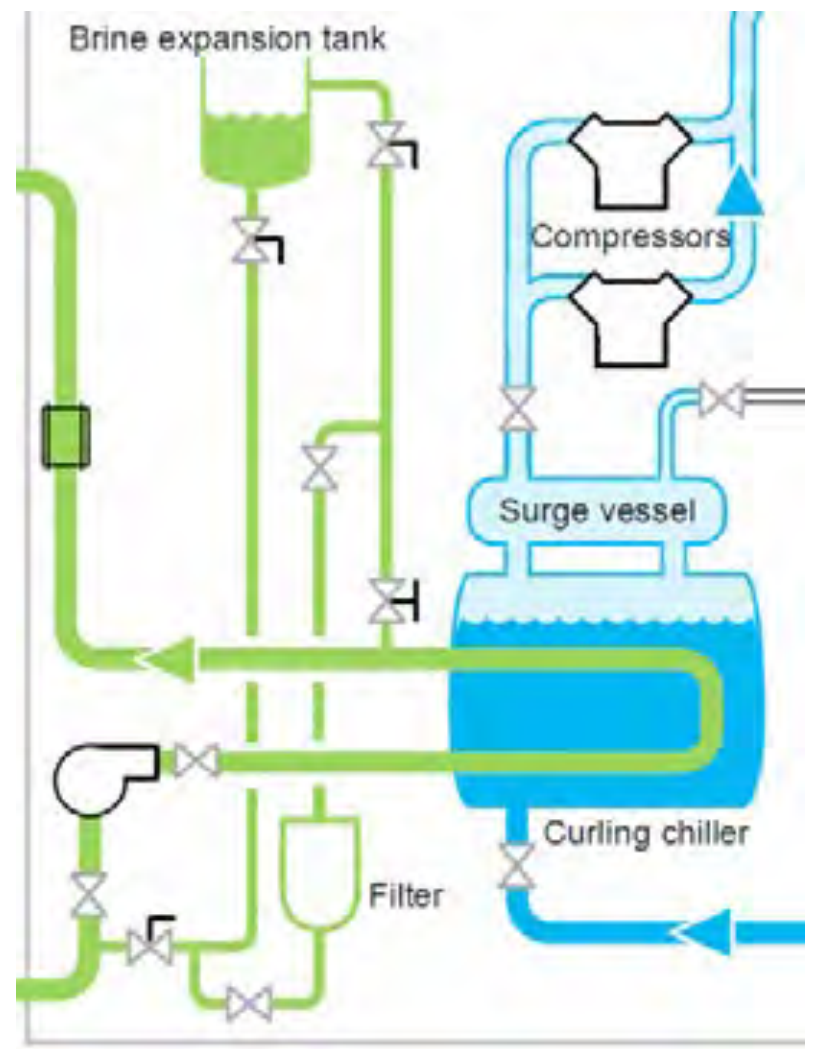

Fig. 5. Fernie Ammonia Chiller [12]

\section{OBSERVATIONS}

The goal of the changes was to boost student engagement and to better utilize student contact time. The course has always been well received and the student response in course evaluations has been well above the average for the University, the Faculty and the program. We wanted to ensure that the courses strengths were not diminished by the changes. A key learning outcome is that the students develop the ability to consider deviations to a design intent, and to develop strategies to prevent the deviation as well as to plan mitigation strategies.

The course works well because the project has been made to be active, collaborative and cooperative [12]. The students have the ability to make decisions - the reward is on how they arrived at their decision, and not on the decision itself. The supporting instruction is all done in small groups, and the discussions are always supportive (or cooperative). Futhermore, students receive continual and consistent feedback throughout the course.

The video content was favourably received. The details surrounding the Bhopal and Fukushima cases lends well to video, and the students were able to appreciate the implications of the decisions related both to prevention, as well as those related to mitigation, after the accidents.

An e-learning module introducing Process Safety Management was used and well received. This is an "industrial" module, making it more practical and less theoretical. This provides a means to document student understanding of these issues for accreditation documentation purposes.

The two student groups that choose an environmental project were pleased. Both groups considered a waste water treatment lagoon, which linked to their elective courses. Both groups had to create a plug flow reactor in series model, similar to the models created by the groups considering a traditional chemical process. They were able to consider deviations in their processes, and to develop a P\&ID and control strategy to accommodate typical upsets.

The group that developed a CSTR model for the lithium extraction, followed by the physical separation process to yield lithium carbonate were also enthusiastic and engaged. The deviations and P\&ID considerations were very different than those for the chemical synthesis process. There were also key learnings for this group around solids handling that are not covered elsewhere in the curriculum.

The group that chose to review a case study developed a fluid mechanics model for the BOP Macondo oil release. They learned about bowtie analysis, and applied it in their considerations.

It is interesting to note that the case study students were above average, but not top of the class. The common feature was a desire to go into business (MBA), rather than process engineering. The use of the bowties and risk calculations (hazard consequences * probability) were their key learning outcomes.

Indeed, none of the students in the four "pilot" groups were near the top of the class. They were good students, with grades closer to the class average. 


\section{OUR TAKEAWAYS}

Our key takeaway is that providing some degree of choice in the design project was positively received. This was not a surprising result to us. There is skepticism about loosening the "rules" surrounding design activities, albeit generally not from those who run the design project courses.

The success of these changes is providing us the ability to expand the concept to other programs. It would be easy to create a mineral processing project, which would feed into a hydrometallurgical extraction project, thereby linking two disparate programs.

The other key takeaway is the confirmation to us that use of the "Deviations Analysis" provides a structured methodology for identifying hazards and hazardous scenarios. The approach enables exploration of the knockon effects of a change. Indeed, student response to course survey questions showed a large number of responses indicating a positive response to learning how to achieve the "shared values" of design for safety, which is more than just performing a sizing calculation.

There is a range of student competencies in the use of the approach. As a minimum, students will identify the need for measurement and control, and then add alarm points. Many students will be able to see the process more holistically - a controller on an upstream process defines the inlet to a downstream unit (or one doesn't need a pump after each unit to account for the pressure drop in the unit). The top students will build in a control strategy including logic control for interlock functions.

The next steps in the continued development of the course is to develop a strategy to expand this course into a second program, as well as to expand the range of project choices. We also intend to develop more e-learning content to address common questions posed by students in the class, and to eventually eliminate the traditional lecture component of the course.

\section{Acknowledgements}

Both authors would like to acknowledge receipt of a TEAL Fellowship from the Faculty of Applied Science and Engineering, University of Toronto.

\section{References}

[1] Canadian Engineering Accreditation Board, 2018 Accreditation Criteria and Procedures, Ottawa, ONT: Engineers Canada, 2018123 pp \{ISSN 1708-8054\}

[2] Yang Luo and Philip Westmoreland, "Chemical Engineering Academia-Industry Alignment: Expectations about New Graduates ,American Institute of Chemical Engineers (AIChE), 2015, 55 pp Available from https://www.aiche.org/sites/default/files/docs/conferen ces/2015che academicindustryalignmentstudy.compre ssed.pdf

[3] Richard M. Felder and Linda K. Silverman, "Learning and teaching styles in engineering education," Engineering Education, vol. 78, no. 7, pp. 674-681, 1988.

Available as of March 3, 2012, from http://winbev.pbworks.com/f/LS-1988.pdf

[4] Robert Cornesky, The Quality Professor Implementing TQM in the Classroom. Madison, WI: Magna Publications, 1993209 pp \{ISBN: 0-912150-297\}

[5] Steve Condie, One Night in Bhopal, London UK, BBC, 2004,

Available from http://news.bbc.co.uk/2/hi/programmes/4024015.stm

[6] Satchit Balsari, Lindsey Garrison and Jennifer Leaning, Fukushima Daichi: The Path to Nuclear Meltdown, Hong Kong, The Hong Kong Jockey Club Charities Trust, 2016 Available from http://www.hkjcdpri.org.hk/elearning/fukushimadaiichi-path-nuclear-meltdown

[7] Parnian Jadidian and Graeme Norval, Improving Safety Education and Culture in Academic Institutions using a Scaffolded Online Curriculum, $68^{\text {th }}$ Canadian Society for Chemical Engineering Conference, (Toronto, ONT; 28-31 Oct, 2018), 2018

[8] National Commission on the BP Deepwater Horizon Oil Spill and Offshore Drilling, Deep Water; The Gulf Oil Disaster and the Future of Offshore Drilling, Washington, 2011191 pp \{ISBN 978-1-100-24860-8\} Available from

https://www.nrt.org/sites/2/files/GPOOILCOMMISSION.pdf

[9] Transportation Safety Board of Canada, Railway Investigation Report R13D0054 Runaway and MainTrack Derailment, Gatineau, QC, 2014398 pp \{ISBN 978-0-16-087371-3 \} Available from http://www.tsb.gc.ca/eng/rapportsreports/rail/2013/r13d0054/r13d0054-r-es.asp

[10] U.S. Chemical safety Board, Key Lessons for Preventing Inadvertent Mixing During Chemical Unloading Operations, 2017, 48 pp

Available from https://www.csb.gov/mgpi-processinginc-toxic-chemical-release-/

[11] Technical Safety BC, Investigation Report: Ammonia Release - Fernie Memorial Arena, 2018, 41 pp. Available from https://www.technicalsafetybc.ca/fernieinciden

[12] Michael Prince, "Does Active Learning Work? A Review of the Research?", Journal of Engineering Education vol. 93, no. 7, pp. 223-231 2004. 